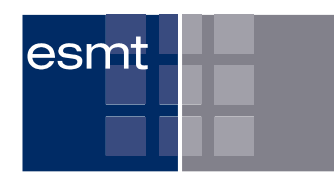

european school of management
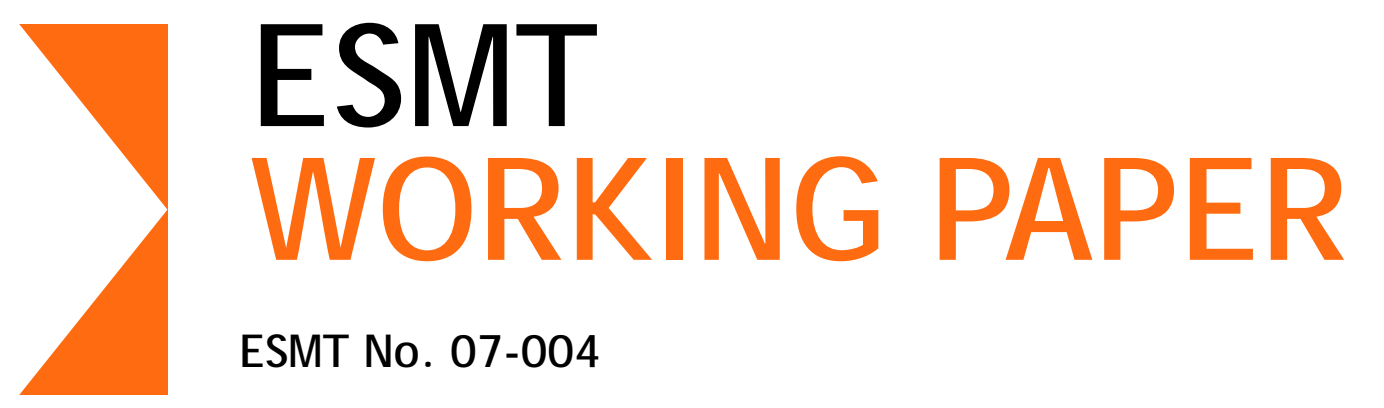

ESMI No. 07-004

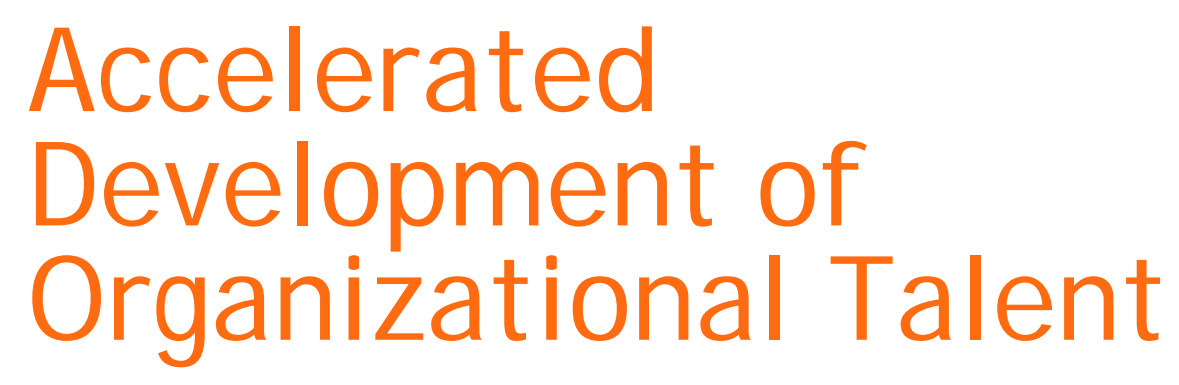

Konstantin Korotov, ESMT

ISSN 1866-3494 


\title{
Abstract
}

\section{Accelerated Development of Organizational Talent}

\author{
Author(s) ${ }^{*}$ : Konstantin Korotov, ESMT
}

This working paper explores the challenges of accelerated development of organizational talent. The meaning of the word "accelerated" is that such development takes place at a pace that is significantly higher than that of "traditional" development that allows an individual to learn the intricacies of the current job, observe incumbents in a higher level position (usually, one level up), practice elements of the boss' job when being delegated tasks, undergoing formal training, or benefiting from the knowledge accumulated by others and codified in the knowledge management systems. Accelerated development means, contrary to the usual, more traditional developmental path, bypassing traditionally expected career steps, stretched over a longer period of time learning opportunities, and/or age-related developmental progression. Accelerated development is a necessity for organizations facing unprecedented growth, lack of qualified individuals in the internal or external labor markets, and significant pressures from other organizations that are ready to "poach" talented executives and employees and offer them even higher levels of responsibility and remuneration. Organizations also respond with accelerated development initiatives to the individuals engaged in career entrepreneurship, i.e., those who make alternative career investments in order to enjoy quicker returns in terms of career growth and progression.

This paper discusses the challenges of accelerated development programs, such as not only learning the competencies required in the new position, but also developing a new identity. The paper discusses the process of going through an accelerated development program and identifies its important elements: preentry experience, initial surprise of getting into the accelerated program's environment and learning to use it, engaging in identity exploration through examining past and present identities, staging identity experiments, and, finally, stepping out of the program into the real world.

Keywords: organizational behavior, human resource management, executive education, identity, accelerated development. Konstantin Korotov (ESMT), Phone: +49(0)30 21231-1299, Fax: +49 (0) 30 21231-1281, Email: korotov@esmt.org. 


\section{Accelerated Development of Organizational Talent}

Organizations in many parts of the world are experimenting with ways to speed up the development of their management and employee talent in order to respond to current and anticipated pressures from the marketplace. They aim to equip organizational members with the skills, knowledge, attitudes, and behavioral patterns necessary for success in the future roles and tasks. Those future roles and tasks are perceived to be more challenging and important than the ones currently held by the accelerated development program incumbents. At the same time, preparation for the next steps in one's career is combined with the expectation of ongoing success in one's current position. Stepping up to the next level is contingent upon doing extremely well in the current role, (over-)achieving the targets set, and demonstrating readiness for the next challenge. Accelerated development may also take place as part of the organization's succession management efforts. In preparation for an expected promotion of an executive, knowledge needs to be transferred to his or her potential replacement, and the latter needs support in preparation for the new job. Thus in effective accelerated development and broader succession planning and implementation efforts we can see an essential link between talent management and knowledge management.

Following Abel (2005), the challenge of a person going through a high-speed developmental journey in modern organizations is in the dual requirement of being excellent in the current job while preparing to take a significantly more challenging responsibility ahead. A person put on some kind of an accelerated program, at the time of being nominated for it, is often judged based on his or her professional and/or managerial potential and the degree of fit with the role ahead. However, while undergoing the developmental effort, he or she is most likely to be simultaneously judged on current successes and failures, and will be constantly reassessed in terms of the fit for the future expected position. The challenge for the 
organizations is to make sure that individuals are supported in their current jobs and in preparation for the new roles. In a clear fusion of talent and knowledge management, these organizations need to manage transfer of knowledge within the talent pool in the most effective and efficient way.

The meaning of the word "accelerated" is that such development takes place at a pace that is significantly higher than that of "traditional" development that allows an individual to learn the intricacies of the current job, observe incumbents in a higher level position (usually, one level up), practice elements of the boss' job when being delegated tasks, undergoing formal training, or benefiting from the knowledge accumulated by others and codified in the knowledge management systems. Accelerated development means, contrary to the usual, more traditional developmental path, bypassing traditionally expected career steps, stretched over a longer period of time learning opportunities, and/or age-related developmental progression. Accelerated development is a necessity for organizations facing unprecedented growth, lack of qualified individuals in the internal or external labor markets, and significant pressures from other organizations that are ready to "poach" talented executives and employees and offer them even higher levels of responsibility and remuneration. Organizations also respond with accelerated development initiatives to the individuals engaged in career entrepreneurship, i.e., those who make alternative career investments in order to enjoy quicker returns in terms of career growth and progression (Korotov \& Khapova, 2007).

A recent discussion with a leader responsible for the life-long learning and development of Europe-based partners in a global professional services firm has underscored the accelerated talent growth challenge faced by this organization and its direct competitors. In talking about challenges of managing partner development across many countries, she mentioned that in 
some markets where this global firm operates partners in the national leadership positions are in their late 50s, which is a traditional age to make it to the top at a national level in that type of organizations, while in a number of markets, particularly those that are characterized by dynamism and unprecedented growth, national practice leaders nowadays often get to that level in their mid- to late-thirties (the age when in "traditional" economies people are often only considered to be put up for a partnership vote). If people rise to the top significantly earlier, and if their respective organizations encourage (or are forced to tolerate) such quick rises, there is simply no time for a traditional, "slow" career development path and growth time. In another professional services organization, a competitor of the one mentioned above, a partner responsible for talent development commented, for example, that his organization needed to find new ways of growing and developing partner candidates and young partners, as some of them made it partner in their late 20s! Many of them started to work early, when still in college, and, given the professional opportunities of quickly growing markets, they managed to gain success and quick career progression very early. The young age of the partners, however, made the organization face new and not previously known challenges about personal maturity of the young partners, the issues of wisdom, client relationships, etc.

In a different setting, leaders of a global FMCG company got concerned that their AsiaPacific operations continued to depend heavily on the expatriate pool generating in Europe or North America to run its business in the region. The company’s leadership established it as a target to significantly increase the number of local nationals in the top-tier regional management positions within a short period of time. The leadership team defined the time as two years. The challenge faced by the organization (and, by extension, the executives in the Human Resources and Learning and Development functions) was manifold: on the one hand, to truly equip candidates for the top positions with the competencies necessary for success, on the other, to convince the rest of the organization, including top decision makers at the 
worldwide level, that the local talent was ready for the job. In addition, it was considered necessary to make sure that the regional talent also saw themselves as capable of taking over the top leadership jobs in the region and succeed in them.

Learning and development at a pace that is higher than usual is not completely new to organizations. Quite a few companies have been long experimenting with so called "fasttrack" or "high-flyer" development programs for specially selected cohorts of fresh college graduates or newly-mint MBAs. Incumbents in such programs would typically be recruited with a specific expectation that they would reach management positions in a shorter period of time than would be the norm for non-fast-track people. During a usually two-year long program these management trainees would be put through a series of rotations through different organizational functions and/or geographical locations allowing mastering various managerial competencies. It looks like with program like these some modern organizations respond to the growing number of young people who are looking for an accelerated development opportunities and want to bypass traditional career steps and do not want to take a traditional path to their career development. For example, in various countries of the world, Unilever for the past forty years runs a special accelerated development program, Unilever Graduate Recruitment and Development Program - UGRDP. Recently Unilever Russia has put on its web-site information about Maxim Popov, the youngest of the participants in such a program. At the time of writing this chapter, Maxim was only 20 years old. However, in twoyear's time, after going through an accelerated learning and development program involving rotation through different organizational functions and locations, he was expected to become a manager in one of the Unilever's functions in Russia or in Europe (www.unilever.ru/ourcompany/careers/Work_for_graduates/UGRDP2006.asp). Companies that have formally structured opportunities for accelerated development of young candidates for managerial positions, usually pay very careful attention to the selection of participants in 
such programs, design structured training programs, ensure on-the-job exposure of incumbents to important organizational issues and opportunities to work with experienced mentors, manage rotation through various job posts and geographical positions, and, eventually, ensure a careful placement of program graduates in their first independent "postdevelopmental” management roles.

Programs for high-flying graduates and their challenges have received attention in the organization's literature. Larsen $(1996,1997)$ asserts that such programs, in their traditional format, often end up being a tool for participant's individual career development and fail to respond to the strategic needs of the organization. Kovach (1986) discusses potential negative outcomes to graduates of high-flyer programs who may learn behaviors that are conducive to success at early stages in their careers, but potentially detrimental as they move to executive positions. Viney, Adamson, \& Doherty (1996) stress that initially high-flyer programs were seen as pure learning opportunities for its incumbents with no expectation from latter to contribute in a significant manner to the organization's results. With the increasing competition, however, in many organizations those arrangements got changed: companies started to expect business results from their management trainees relatively early on leading to the paradoxes of having to cope successfully with the tasks that are still being learned.

Larsen (1996) calls for a link between career, organizational development, and competitive advantage of organizations. The accelerated development programs should not be restricted to initiatives for quicker advancement of fresh graduates but rather look at a broader pool of management talent in order to answer to this call. Companies, as mentioned above, use accelerated development programs as ways of coping with the market pressures. They look at various cohorts of managers, and not just newcomers. Importantly, there is not just transfer of knowledge to the incumbent: the latter also have to transfer their knowledge to other people in 
the organization. Such programs often involve a component that deals with helping the incumbent develop his or her subordinates or prepare a successor before they can move to the next position.

It also should be noted that the opportunities and challenges of accelerated development of talent are important not only for organizations that are developing elite candidates for the management ranks. Similar issues are important for considering developmental opportunities for rank-and-file employees who need to be prepared for changing requirements of the marketplace or evolving needs of clientele. For example, Kets de Vries, Shekshnia, Korotov, \& Florent-Treacy (2004) describe entrepreneurial efforts of new business leaders in Russia. A founder of a consulting company engaged in the field of Enterprise Resource Planning Systems was initially forced to hire her employees among university students, as she couldn't afford to pay people who had already completed their degrees. Although the studentemployees had sufficient technical knowledge (as they were coming from very respectful technology-oriented schools), they completely lacked business acumen, social skills necessary for dealing with clients (and co-workers), and even an understanding of their own personal or career development. With the expansion of what became a very successful business, increased complexity of consulting activities, growing sophistication of clients, and a bigger emphasis on the bottom-line results, the organization's founder had to start thinking about quickly developing her staff to meet the competencies shortage challenges. Ironically, coming from a purely scientific background, she herself had to quickly learn about management and leadership, and about how to support the development of others. It should be noted, however, that in the majority of cases organizations are referring to preparation of people for higher levels of management and leadership responsibilities when they talk about accelerated development. 
The ways of developing people in an accelerated manner differ significantly from company to company and country to country. For instance, in Russia's Gazprom, one of the world's largest and most successful corporations, about 1200 university graduates start their careers every year. Their socialization into the company and their whole development process in very many cases starts with a blue-collar position, where newcomers with 5 or 6 years of university studies behind their back do work that typically requires only a couple of months of on-thejob training. In case of success in one of the blue-collar positions, employees may be selected for white collar jobs and later for further growth and development opportunities managed through the corporate university (Sheveleva, 2007). British-American Tobacco has traditional high-flyer programs for university graduates and, at the same time, accelerated growth programs for managers, where the focus is on executive competencies and leadership skills (Taylor, 2006). Ernst \& Young in some markets has programs for partners that are geared at equipping them with the competencies needed to manage their respective practices and become leaders among very successful partners.

\section{Developing a New Identity through Accelerated Development Programs}

A critical issue in the process of accelerated development is not just a set of skills or knowledge that a participant in such a program has to master, but also the development of a new identity, a new sense of self that is claimed by the person him- or herself, and that is supported by the organization and people around the individual. Getting prepared for a new role (e.g., that of a manager instead of an individual contributor, that of a partner instead of an employee, or that of a national business leader instead of a top manager) has been shown to require a significant change in one’s professional identity (e.g., Hill, 1992). Kovach (1986) notices that failure to manage transitions and learn how to deal with the changing expectations of the organization as one moves to the next career level often leads to derailment of fasttrack employees. 
New levels of responsibility, being in charge of other people, stepping into the shoes typically reserved for more "mature” people, requires certain changes in one’s view of him- or herself. Thus, accelerated development programs, if they are to prepare people for a new role that requires a new identity, need to create opportunities and provide support and resources for crafting this new sense of self that is associated with the new role. When working on a new identity, as suggested by Ibarra (2003, 2004), individuals need to start doing new things, start developing new networks, and start telling a new story about themselves.

\section{Start Doing New Things}

While doing one's job today, participants in accelerated development initiatives in organizations have to learn the intricacies of their future job. They have to simultaneously cope with today's responsibilities and be successful in taking on pieces of work that are not typical for their current organizational position and level of responsibility. To be truly developmental and to contribute to the necessary perception by the organization of the manager going through accelerated development as a successful one, such projects need to be closely tied to the real business needs of the organization, and they need to be highly visible for organizational members. Organizations and their leaders (and not just HR professionals) need to identify real projects or processes that bring with them important opportunities for the organization. The projects or work on processes need to have a powerful sponsor at the top of the organization who is interested in the success of the project and people involved in its implementation, and who has the time and energy to spend with the members of the project team (many or all of whom may be involved in the accelerated development program). In order to succeed in both, their current job and the new project, participants on the accelerated track need to have enough time and other resources and visible support, including ongoing mentorship from committed experienced leaders. 
The projects need to be perceived as important not only by the organizational leadership, but also by other managers and often even the rank-and-file employees in the organization. If the accelerated development program reaches its goals, its participants will eventually gain higher level positions quicker than normally expected by the organizational members. These executives must be able to claim their psychological right for such a position. In their turn, managers and employees need to "accept" the person who has received his or her promotion by the means of accelerated development as a legitimate incumbent in the new position in order for him or her to be successful in the new role. In terms of Bartel \& Dutton (2001), new identity has to be claimed by the individual and granted by people in his or her surroundings, which requires identity work from all those involved.

In addition to the responsible project work, participants in accelerated development programs have to demonstrate that they are doing new things in their daily interactions with the people around. For example, they are expected to be delegating more of their tasks to the subordinates, give them more feedback and coaching, while simultaneously clearing more time for themselves in order to get engaged in new activities. Obviously, this is easier said than done. Managers on the accelerated track usually need support in learning to delegate tasks to their employees and guide them through their work without micromanagement. Such support involves formal training in delegation skills, introduction to coaching techniques for managers, and mentoring from more experienced colleagues or help from an executive coach.

With an increased move in the direction of knowledge work, designing and developing accelerated development programs needs to take into account the specifics of today's knowledge workers. Davenport (2005) defines knowledge workers as individuals with high degrees of education, experience, or expertise involved in jobs that create, distribute, or apply knowledge. One of the first fundamental features of knowledge work is its lower propensity to 
being structured, thus leading to a need in a higher autonomy of the employee engaged in such work. The autonomy is particularly important in the way the work is organized, how people work towards their targets. Such a feature of knowledge work may become an important difficulty for both people undergoing accelerated development and those around them. On the one hand, people on the accelerated track may be "clinging" to their field of expertise or the competencies that they have developed and displaying which they feel confident and comfortable. On the other, individuals around them may not easily accept the move of the incumbents into new territories. Organizations also need to make sure that the knowledge that is required for the incumbent's current role gets passed on to those who will take over when the person under development moves on. There is a need for ways of capturing his or her current knowledge and passing it to other people. At the same time, there is also a need to understand what the incumbent needs to "unlearn," or learn to stop relying on when the move to the next level is made.

Those on the accelerated track need to delegate tasks and transfer knowledge to their subordinates, and simultaneously they also need to be delegated new responsibilities and be given new chances. That requires readiness to do so from the people above and around the talented manager or employee. Top executives need to be ready to share responsibility and accountability, resources (including the knowledge accumulated in their position), contacts, etc., with the incumbents of accelerated development programs. Davenport (2005) argues, however, that for knowledge workers sharing is unnatural, especially today when there is an ever increasing fear of competition from all quarters, and individuals on the accelerated track may be perceived as explicit competitors. Thus, in companies that use, for example, fast-track graduate development schemes there may be open or subtle resistance on the part of the employees to share their knowledge with the trainees who could eventually become their bosses without a long-term organizational tenure. As expressed by an HR executive, 
sometimes the trainees are at fault: they create an impression that they act with an attitude of superiority due to "having been selected”, and, as a result, fail to gain cooperation and support from the people who have the necessary knowledge that needs to be shared. This practitioner's concern about the negative side of the elitist nature of high-flyer programs is also documented in the literature (Larsen, 1997). Obviously, working on the right attitude comes as part and parcel of the overall accelerated development approach. Gaining cooperation from the organizational members and learning how to elicit knowledge from the people who have it thus becomes a critical competence on the way to acquiring skills and competencies for the higher level job.

\section{Developing New Networks}

Following Ibarra (2003, 2004), a new identity requires a new network - a new circle of professional and sometimes social contacts that would allow a participant in an accelerated development program to establish a new sense of self and get a confirmation of the acceptance of this new sense of self from the people around. An accelerated development effort, therefore, should include opportunities for meeting new people and learning to establish a new set of relationships at a different, usually higher level in the organization and its surroundings.

For an incumbent in an accelerated development program to be successful in the development of the new network, again, time, resources, and commitment from mentors or program sponsors are necessary. One of the critical resources is the desire of the person above the incumbent (e.g., his or her boss, mentor, program sponsor, etc.) to offer him or her access to their own networks, introduce them to new people, communicate the expectations the organization has of that particular individual, etc. New contacts and relationships involve higher-level management, executives from a different part of the organization (e.g., from 
another country’s operations or global headquarters), clients, suppliers, government contacts, professional bodies or industry associations, academics, journalists, etc.

An introduction to a new network, however, is not sufficient. The incumbent needs to learn to use the network productively: to contribute to the well-being and success of the others involved in order to be able to rely on the contacts when needed. As people vary in their abilities to establish relationships, additional support may need to be provided to the incumbents. This support can be in the form of training, mentoring, or coaching. Sometimes sharing with the incumbent of the mentor's experience in developing professional networks serves as a powerful motivational input for the incumbents of accelerated development programs. At times, support from more experienced and established mentor or sponsor is necessary in order to help others accept the incumbent as a worthy addition to one's network. Kets de Vries, Shekshnia, Korotov, \& Florent-Treacy (2004) describe how a talented and competent, but young (in his early 20s) consultant from a new generation of Russians faced a challenge of acceptance from a "traditional” Soviet-type director who would simply refuse to talk to him and demand presence of the General Director of the consulting company to discuss the issues that the consultant was perfectly competent in.

\section{Developing a New Story about Self}

Ibarra (2003, 2004) and Ibarra \& Lineback (2005) suggest that making a transition to a new identity is not possible without having developed a new story about oneself. What and who a person is get communicated to self and the people around through the narratives developed by people taking on a new identity. The narrative about oneself is accepted by the protagonist and then transmitted to the organizational members and other stakeholders in the accelerated development process. In order for the message to be effective, the protagonist, obviously, has to believe in the logic of the new story him- or herself. Development of such a story may take 
time, as normally the sense of who we are develops in us with the experiences, reflections, dramas, and successes we go through over years. The challenges in the accelerated development program is to make sure that this story, developed over a significantly shorter period of time, has enough substance in it in order to be credible, and is structured in such a way that the "audiences" of the story accept the expected wealth of experience, skills, competencies, etc. as legitimate despite the time constraints in terms of developing them.

Working out on a new story about self (e.g., that of a manager, and not a fresh university graduate, a leader of a professional services practice, and not a tax expert, a manager of managers, and not a manager of a team, etc.) often requires a push and enough support. Usually it involves iterations of trying and getting feedback, and then trying and getting feedback again and again. Obviously, for such an interactive process a relatively safe environment and qualified feedback-providers, guides, and helping “ears” may be required.

The tasks listed above are not for the faint of heart. Given the challenge of doing one's current job and being successful in it, while simultaneously preparing for a new one, and showing consistent progress and signs of success, may be daunting. Among those who are selected into accelerated development programs there often are what Kets de Vries (2005) calls sufferers of the impostor, a fake syndrome, insecure overachievers. The people suffering from the impostor syndrome are often driven by a fear that at certain moment the organization is going to recognize that they are not as good as they seem to be. Usually accelerated development programs attract a lot of attention from people at different levels in the organization. Under such an increased scrutiny, the challenge of dealing with the impostor syndrome becomes even more acute. As a result, the insecure overachievers impose extremely high demands on self and others, and sometimes overstretch themselves and the people around. It is important, then, that as a result of the accelerated program, participants have a realistic view of 
themselves, a positive outlook on their competencies, and readiness to accept whatever limitations they may have. The learning aspect of a development program suggests that people make mistakes as they do new things, establish new networks, or tell new stories about themselves. Organizations need to be prepared to let some of the mistakes happen without the drastic consequences for the incumbent in an accelerated development program. However, as mentioned in an official description of such a program in a global company, participants are constantly under watch and constantly judged with respect to how well they meet the organization's expectations.

The issue of understanding (and sometimes accepting) one's limitations is equally important for the roles the incumbents prepare themselves for. One of the ways of avoiding potential disappointment associated with the new roles (which quite for some time probably seem to be an important objective for the incumbents) is through realistic job previews (Wanous, 1992). Although future positions may look attractive to an organizational member, he or she should also be aware of the challenges associated with the new job. For example, leadership positions in general have been shown to carry with them a number of psychological burdens. Thus, people who have made it to a position of significant responsibility often face the feelings of loneliness of command, fear of envy, the "what's now?" syndrome, being constantly under watch, feeling of personal guilt, an ever steeper learning curve, etc. (Kets de Vries, Korotov, \& Florent-Treacy, 2007). As part of the accelerated development, individuals getting ready for these roles need to learn how to prepare for facing the situations (and their own feelings about the situations) that they are not yet familiar with, because they haven't experienced them. The principle of realistic job previews is based on the idea that people receive accurate information about their future role(s) that covers both the sources of satisfaction and dissatisfaction for role incumbents. Getting realistic information about the future role helps employees make a better decision about accepting the opportunity, and serves as a form of 
inoculation against future dissatisfying factors. Besides, Wanous (1992) suggests that realistic job previews serve as mechanisms of anticipatory socialization and help individuals develop coping mechanisms eventually contributing to the success on the job.

Realistic job previews can be viewed as a way of transferring knowledge about what the job really entails in order to increase the effectiveness of the future incumbent when he or she moves into a new position. Obviously, despite the generic attempts of codifying such knowledge (e.g., the above mentioned challenges of becoming a leader in general (Kets de Vries \& Korotov, 2007)), the bulk of the knowledge remains to be organization and position specific. The transfer of such knowledge is then possible only through specific intraorganizational efforts. One of the ways is mentoring of the incumbents by more experienced organizational members. Similarly, knowledge about organizational politics, social networks, interaction patterns, and personal likes and dislikes gets transferred either through informal channels or mentoring efforts, requiring special effort and readiness from both the mentor and his or her protégé.

\section{Accelerated Development Programs as Identity Laboratories}

All of the above considerations suggest that an accelerated development program is a multifaceted undertaking on the part of the organization with clear implications for a solid commitment to effective knowledge management. An accelerated development program effort also requires various skills and inputs from all the people involved: the incumbents, program organizers, sponsors, mentors, and all others involved. Moreover, an accelerated development program has multiple learning outcomes that go beyond the more or less obvious functional knowledge and skills and understanding of how the organization functions. These learning outcomes include, but are not limited to, the following elements:

- Ability to learn new identities 
- Ability to deal with the impostor syndrome (Kets de Vries, 2005)

- Realistic preview and sense of the reality of the roles ahead

- Ability to experiment and cope with both success and disappointment and failure

- Development and management of new networks

- Design of a new "story" about self and the people around

- Acceptance of the incumbent in his or her new role by the organization.

All the above suggests that in order to be successful, an accelerated development effort has to lead to a transformation of its participants and their emergence with a new identity within the organization. But how can organizations create opportunities and conditions for such transformations? Recently there has been a renewal of interest in the potential offered by the psychodynamic concept of transitional space (Winnicott, 1953) and the anthropological concept of liminality (from threshold in Latin) (van Gennep, 1909) in exploring ways of how people achieve personal and professional transformation.

In one model of the identity transition process associated with radical career change (Ibarra, 2004, 2005), for example, there is special room given to liminal experiences and transitional phenomena. Liminal (in-between) experiences are traditionally characterized by a feeling of being between identities, being suspended, being in no man's land, and the ugliness of being in the middle (Ashforth, 2001, Ebaugh, 1988). Nevertheless, regardless of their possible negative aspects, such experiences are also thought to give motivation and opportunities for people to imagine new alternatives to their current situation, with failure to do so often being the biggest stumbling block on the road to personal and professional transformation (Ibarra, 2004). Transitional phenomena (i.e. phenomena similar to transitional objects in their functions (Winnicott, 1953)) are conceptualized to provide resources and conditions for people to put identities into play (in other words, opening existing identities to change and 
trying out new possible selves). Recent literature on transitions draws researchers' and practitioners' attention to the concept of transitional spaces, or special privileged areas that are set apart from mainstream activities and have a legitimate status as a place for experimentation and creativity (Amado \& Ambrose, 2001; Ibarra, 2004; Korotov, 2005, 2006).

Transitional spaces create opportunities for play and experimentation, help the people inside them overcome change-related anxieties, offer novelty that gives an extra boost to desire for changing the self, impose certain rules and structures that are counter-normative to what exists in the world beyond the transitional space, set psychological, temporal and spatial boundaries, and offer a menu of guiding figures to people inside the space. All these elements together create the potential for identity experimentation and renewal. There have been specific indications in literature and in practitioners' work that adult education and development programmes can create spaces conducive to identity exploration and experimentation and provide element of transitional space and liminal experiences (Ibarra, 2003, 2004; Kets de Vries, 2006, Kets de Vries and Korotov, 2007, Korotov, 2005, 2006).

To be successful, an accelerated development program has to have elements of an identity laboratory, because, as mentioned above, it is expected to lead to a change in one's identity in quite a short period of time.

Identity laboratories can be conceptualized as special transitional environments demarcated temporarily, spatially, and psychologically from the rest of the identity-granting world. It provides the conditions for practicing elements of the new identity in a safe environment within the laboratory boundaries, and at the same time allows to take some of the experimental outcomes into the real world of work and life. The laboratory is "equipped" with identity exploration and experimentation opportunities, guiding figures or facilitators, and 
tools, such as transitional objects that participants need to learn to use to go through the laboratory productively. An identity laboratory environment is suitable for people who are in a liminal stage in their identity change process, i.e. "neither here nor there” (Ebaugh, 1980): in the process of disengaging from the old identity without having fully left it, and in the process of developing a new one, without yet having fully embraced it. The above-mentioned duality of the position of the person in an accelerated development program (e.g., being both under watch for success in the current role and constant assessment of the fit for the future role) makes it safe to say that an incumbent of such a program is very similar to the "neither here nor there” position. More exactly, he or she is actually both "here and there”, in the present and in the future.

To truly turn their accelerated development program into identity laboratories, organizations need to take into account that participants need to learn to truly benefit from the opportunities of experimenting with a new sense of self. Previous research (Korotov, 2005, 2006; Kets de Vries, 2006, Kets de Vries \& Korotov, 2007; Kets de Vries, Korotov, \& Florent-Treacy, 2007) suggest that an identity laboratory experience usually has a number of important elements in it. These elements include pre-entry experience, initial surprise of getting into the accelerated program's environment and learning to use it, engaging in identity exploration through examining past and present identities, staging identity experiments, and, finally, stepping out of the program into the real world.

\section{Pre-entry Experience}

Before admittance to the accelerated programs, participants usually engage in a heavy dose of assessments and competition, or, as a minimum, discussions with their mentors or bosses. Officially designed to assess the fit between a candidate and the future role requirements these pre-program activities per se triggered some of the initial learning that would later grow to a 
full-fledged dimension as the program unfolded. The selection process reveals some of the elements of the future roles and the accelerated development path and triggers potential participants' curiosity about themselves and their future. The selection activities can serve as sampling of the unusual nature of the developmental path and as a rule-setting mechanism, the start of individual psychological contracts and commitments to future actions such as readiness to engage in the accelerated development program at cognitive, behavioral, and emotional levels required for a true identity transformation (Kets de Vries \& Korotov, 2007).

The pre-entry experience, apparently, is important for accelerated talent development programs in order to contribute to the formation of the incumbents' expectations and fantasies about their forthcoming learning and experimentation experience, including the initial feeling of psychological safety of experimenting during the program. It also gives participants a preview of what is going to lie ahead of them in the program, as well as the rules in the program. As shown by research on transformational executive programs, participants' learning often starts before their official start in the program, namely, during the selection and preparation stages (Kets de Vries \& Korotov, 2007).

\section{Surprise and Learning to Use the Space of the Accelerated Talent Development Program}

Despite the development of preliminary expectations, the actual initial program experience frequently turns out to be different from both the expectations and any kind of previous developmental experience participants had had. The beginning of the program normally brings about surprise (cf. Louis, 1980). Major dimensions of surprise are about the experimental nature of the program and opportunities and challenges that are perceived to be opened by it, as well as the need to explore and engage in one's own identity transformation process. The programs and the developmental assignments often make people realize that their organizations are consisting of people who should be viewed "not as rational agents, as 
passive functionaries, as economic beings or as cogs on a machine, but as distinct individuals, with emotional and fantasy lives, with histories and pasts, diverse emotions and developing identities” (Gabriel \& Carr, 2002: 354-355).

After realizing the novelty, unusualness of their situation of being put on an accelerated development path, which per se is a factor conducive for identity experimentation (Yost, Strube, \& Bailey, 1992), participants need to learn how to use this new environment which hadn't been experienced before. Organizational members engaged in the accelerated development program need to master:

- Managing the boundaries of transitional space of the program;

- Identifying resources and instruments available to them and learning to use them;

- Figuring out the rules of behavior, given their fast-track status, and the limits of those rules.

Organizations may provide incumbents with a lot of resources and opportunities, as well as establish expectations and rules of behavior. However, participants may not necessarily be familiar with those. Besides, many of the instruments provided by accelerated development programs require learning to use them. Thus, working with mentors or coaches, often a new experience for participants, demands learning what can be expected from such an opportunity and how best to use it. In line with the above, Lombardo \& Eichinger (2000) suggest that participants in programs for high potentials need to be agile for learning. Success of an accelerated talent development program may require special efforts in helping participants learn how to use the program in the best possible way.

\section{Identity Exploration: Examining Past, Current, and Future Identities}

An important part of the participants' experience in accelerated talent development programs is self-exploration which happens through both structured activities included into the program 
by design, as well as through individual's exposure to new tasks, roles, networks, and opportunities. People also engage in identity exploration through the overall process of being in an unusual group, going through new types of work activities, getting external and internal feedback (cf. Ibarra, 1999, 2003a), self-reflections, and interactions with other members of the class. The self-exploration process, if we truly expect development of a new identity in participants of the accelerated program, needs to be built into the program as one of its core elements.

The process of exploration often becomes a multidimensional journey, as various aspects of identities, beyond the professional ones, became salient and got intertwined in the process. Participants also get a chance to compare their current view of self with that expected in their future possible role and to internally assess the fit and possible developmental routes. Identity exploration opportunities may come up in various forms during an accelerated development program: assessments and self-assessments, work with mentors and coaches, engagement in group discussions and debriefing or developmental experiences, self-reflection, interviews with incumbents of higher level roles, etc. Based on our knowledge of transformational programs for experienced executives (e.g., Kets de Vries \& Korotov, 2007), identity exploration opportunities are often viewed as premium features of an executive course. Such opportunities should be promoted and included in accelerated development program philosophy and design.

\section{Identity Experimentation}

Participants engage in identity experimentation through both mental experiments, where they were trying to see themselves in a new role or with a new identity or identities, and in more tangible activities associated with experimenting with new possible identities. An important feature accompanying experiments staged by participants in the program is the perceived 
psychological safety of getting engaged in such experimentation. A lot of experimenting requires preliminary discussions and getting “permission” to experiment from the guiding figures, the role of which was primarily vested with the program sponsors and participants' mentors. Although at certain points other participants may become able to play roles of sounding boards, advisors, and peer coaches, in many cases endorsement for identity experimentation should come from the mentors who guide the participant through the accelerated program.

Experimentation in the course of an accelerated development involves both professional and personal sides. It often included playing with options unthinkable or unimaginable before the program, such as moving into a new functional field or living in a new geographical location. As one of the outcomes of the program should be the placement of the incumbent into a role that best fits his or her talents and interests as well as organizational needs, the accelerated development effort should provide the program incumbent with the opportunities to try to estimate the potential fit with the new identity and discuss it with the organization.

\section{Stepping Out of the Executive Program}

The ending of the accelerated development program means a certain turning point for both the participants and the organization. The end result is the perceived readiness for taking the new role, demonstrated through results achieved in the process of work during the program (doing new things), a set of new contacts and relationships (new networks), and a new view of self communicated to organizational stakeholders (new story).

The program should terminate with another important feature - realization of the importance of the process that the participants had been subjected to for their continuous development in the future. An important take-away from the program, a learning outcome, should be the 
ability to keep developing oneself, keep looking for new opportunities for self, one’s team, and the organization. Hall (2002) calls this a metacompetency of identity learning. Such a metacompetency becomes the foundation for a future growth and development of the talented individual for personal success and the success of his or her organization.

\section{Concluding Remarks}

New roles require new identities associated with them. Preparing talented individuals for the new tasks in an accelerated fashion often requires the need to have people develop a new view of themselves significantly ahead of the "normal" course of one's life and career development. Taking into account this challenge means that the designers of the accelerated programs need to focus not only (and maybe not so much) on the technical aspects of the new roles (e.g., professional skills and knowledge), but rather on the side of what it takes to be ready to succeed in the new role, to be accepted as a legitimate incumbent in the role, to be able to view oneself as someone who enjoys the role, and who wants to be productive and successful in it. This valuable new role information represents a critical content form for knowledge management processes, and again demonstrates the vital link of comprehensive knowledge management in effective talent management. 


\section{References:}

Abel, D. (2005). Leadership Education as a Moving Target. International Journal of Leadership Education, 1(1), 9-21.

Amado, G., and Ambrose, A. (2001). The Transitional Approach to Change. London: Karnac

Ashforth, B. E. (2001). Role Transitions in Organizational Life: An Identity-Based Perspective. Mahwah, NJ and London: LEA Publishers

Bartel, C., and Dutton, J. (2001). Ambiguous Organizational Memberships: Constructing Organizational Identities in Interactions with Others. In: Hogg, M., and Terry, D. (Eds.) Social Identity Processes in Organizational Contexts. Philadelphia, PA: Psychology Press, 115-130.

Davenport, T. (2005). Thinking for a Living: How to Get Better Performance and Results from Knowledge Workers. Boston, MA: Harvard Business School Press.

Ebaugh, H. R. F. (1988). Becoming an Ex: The Process of Role Exit. Chicago: The University of Chicago Press.

Gabriel, Y., and Carr, A. (2002). Organizations, Management, and Pscyhoanalysis: An Overview. Journal of Managerial Psychology, 17 (5): 348-365.

Hall, D. T. (2002). Careers In and Out of Organizations. Thousand Oaks, London, and New Delhi: Sage.

Hill, L. (1992). Becoming a Manager. Boston, MA: Harvard Business School Press.

Ibarra, H. (1999). Provisional Selves: Experimenting with Image and Identity in Professional Adaptation. Administrative Science Quarterly, 44(4), 764-792.

Ibarra, H. (2003). Working Identity: Unconventional Strategies for Reinventing Your Career. Boston, MA: Harvard Business School Press.

Ibarra, H. (2004). Identity Transitions, Possible Selves, Liminality, and the Dynamic of Career Change. INSEAD Working Paper 2004/98/OB.

Ibarra, H., and Lineback, K. (2005). What's Your Story? Harvard Business Review, January: 65-71.

Kets de Vries, M. (2005). The Dangers of Feeling Like a Fake. Harvard Business Review, 83(9), 108-116.

Kets de Vries, M. (2006). The Leader on the Couch: A Clinical Approach to Changing People and Organizations. Chichester: John Wiley \& Sons.

Kets de Vries, M., Shekshnia, S., Korotov, K., and Florent-Treacy, E. (2004). The New Russian Business Leaders. Cheltenham, UK, and Northhampton, MA: Edward Elgar.

Kets de Vries, M., Korotov, K., and Florent-Treacy, E. (Eds.). (2007). Coach and Couch: The Psychology of Making Better Leaders. Houndmills and New York: Palgrave. 
Kets de Vries, M., and Korotov, K. (2007). Creating Transformational Executive Education Programs. Academy of Management Learning and Education, 6 (3):375 - 387..

Korotov, K. (2005). Identity Laboratories. INSEAD PhD Dissertation;

Korotov, K. (2006). Identity Laboratories: The Process of Going through an Executive Program. In: Weaver, M. (Ed.) 2006 Academy of Management Annual Meeting Best Paper Proceedings, August 11-16, 2006, Atlanta, GA, ISSN: 1543-8643.

Kovach, B. (1986). The Derailment of Fast-Track Managers. Organizational Dynamics, 15(2): 41-48.

Larsen, H. (1996). In Search of Management Development in Europe: From Self-Fulfilling Prophecies to Organizational Competence. The International Journal of Human Resource Management, 7(3): 657-676.

Larsen, H. (1997). Do High-Flyer Programs Facilitate Organizational Learning? From Individual Skills Building to Development of Organizational Competence. Journal of European Industrial Training, 21(9): 310-317.

Lombardo, M., and Eichinger, R. (2000). High Potentials as High Learners. Human Resource Management, 39 (4): 321-330.

Korotov, K., and Khapova, S. (2007). Career Entrepreneurship. Paper presented at the 23rd European Group for Organizational Studies Colloqium. Vienna, Austria, July 5-7, 2007.

Louis, M.R. (1980). Surprise and Sense Making: What Newcomers Experience in Entering Unfamiliar Organizational Settings. Administrative Science Quarterly, 25, 226-251.

Shevelkova, O. (2007). Vverkh Po Trube (Up the Pipe) [Electronic Version]. SmartMoney $\begin{array}{lllll}\text { Russia, } & 14 . & \text { Retrieved } & 26.04 .2007 & \text { from }\end{array}$ http://www.smoney.ru/article.shtml?2007/04/16/2730.

Taylor, J. (2006). Predvidet', Vovlekat', Vdoknovlyat', Focusirovat'. (To Foresee, Invovle, Inspire, and Focus). Harvard Business Review Russia, August, 20-21 (In Russian).

van Gennep, A. (1909). The Rites of Passage. Chicago: University of Chicago Press.

Viney, C., Adamson, S., and Doherty, N. (1997). Paradoxes of Fast-Track Career Management. Personnel Review, 26 (3): 174-186.

Wanous, J. P. (1992). Organizational Entry: Recruitment, Selection, Orientation, and Socialization of Newcomers. Reading, MA: Addison-Wesley.

Winnicott, D. (1953). Transitional Objects and Transitional Phenomena. International Journal of Psycho-Analysis, 34: 89-97

Yost, J., Strube, M., and Bailey, J. (1992). The Construction of the Self: An Evolutionary View. Current Psychology, 11(2), 110-121. 





\section{ESMT Working Papers (2007)}

\begin{tabular}{|c|c|c|}
\hline & $\begin{array}{l}\text { ESMT } \\
\text { No. }\end{array}$ & $\begin{array}{l}\text { Competence } \\
\text { Center }\end{array}$ \\
\hline $\begin{array}{l}\text { Estimating Network Effects and Compatibility in Mobile } \\
\text { Telecommunication }\end{array}$ & 07-001 & $\begin{array}{c}\text { European } \\
\text { Competitiveness }\end{array}$ \\
\hline Michat Grajek, ESMT & & \\
\hline $\begin{array}{l}\text { Estimating Level Effects in Diffusion of a New Technology: } \\
\text { Barcode Scanning at the Checkout Counter }\end{array}$ & 07-002 & $\begin{array}{l}\text { European } \\
\text { Competitiveness }\end{array}$ \\
\hline $\begin{array}{l}\text { Jonathan Beck, Humboldt Universität zu Berlin } \\
\text { Michat Grajek, ESMT } \\
\text { Christian Wey, Technische Universität, Berlin }\end{array}$ & & \\
\hline $\begin{array}{l}\text { Usage and Diffusion of Cellular Telephony, 1998-2004 } \\
\text { Michat Grajek, ESMT } \\
\text { Tobias Kretschmer, Ludwig-Maximilians-Universität München }\end{array}$ & 07-003 & $\begin{array}{l}\text { European } \\
\text { Competitiveness }\end{array}$ \\
\hline $\begin{array}{l}\text { Accelerated Development of Organizational Talent } \\
\text { Konstantin Korotov, ESMT }\end{array}$ & 07-004 & Leadership \\
\hline
\end{tabular}




\section{ESMT}

European School of Management and Technology $\mathrm{GmbH}$

ESMT Campus

Schlossplatz 1

10178 Berlin

Phone: +49(0)30212 31-1279

www.esmt.org 